\title{
Damage of porous stones by salt crystallization
}

\author{
M. Keppert, M. Čáchová, J. Fořt, D. Koňáková, \\ Z. Pavlík \& R. Černý \\ Department of Materials Engineering and Chemistry, Faculty of Civil \\ Engineering, Czech Technical University in Prague, Czech Republic
}

\begin{abstract}
Porous sedimentary rocks have been popular construction, decorative and artistic materials for many centuries. Their durability has been an important issue due to their porosity and relatively low mechanical properties. One of the crucial mechanisms of porous rocks deterioration is crystallization of salts in their pores. This crystallization is accompanied by generation of crystallization pressure which can be higher than the strength of the rock and thus cause failure of stone. The paper deals with experimental testing of crystallization damage caused by sodium sulfate. Four kinds of sandstones quarried in Czech Republic are studied; the stones were selected with respect to their different pore size distribution and total porosity. The damage of stones is expressed as their weight loss after cyclic crystallization. The results are correlated with the stone properties (pore size distribution and strength) and crystallization pressure exerted by crystals on the stone. Various methods of crystallization pressure estimation are discussed. Keywords: porous rock, sandstone, durability, strength, salt crystallization, crystallization pressure.
\end{abstract}

\section{Introduction}

The durability related properties of sedimentary rocks were so far studied mainly by geologists from the point of view of rocks weathering. It is generally recognized that salt and ice crystals growth in the pore system is the main deterioration mechanism of porous materials including stones. Standard laboratory tests of rocks durability are based on cyclic immersion in (usually) $\mathrm{Na}_{2} \mathrm{SO}_{4}$ solution, drying at elevated temperature and cooling at laboratory temperature. The difference in specimens mass is used as durability measure. Due to high variability of stone properties (textural, mechanical) the sensitivity to various environmental 
attacks is varying from case to case as well. Benavente et al. [1] analysed statistically factors influencing weathering of porous rocks. The stones strength had higher importance for durability that their pore system structure and water transport properties. Ruedrich and Siegesmund [2] carried out an extensive study of German sandstones focused on their weathering. They concluded that the sandstone resistance to weathering depends on many parameters such are its pore space characteristics (found to be most important), mechanical characteristics and water transport properties. Přikryl et al. [3] studied weathering of Czech marlstone from Přední Kopanina in laboratory conditions. They found this material to be more sensitive to the salt damage than to freeze/thaw action.

Thaulow and Sahu [4] analyzed three possible mechanisms of salt crystallization deterioration of concrete proposed in literature. They concluded that crystallization pressure created by salt crystals growing from supersaturated solution is the reason for salt concrete corrosion. In porous stones the same mechanism can be assumed to be crucial as well. Crystallization pressure exerted by growing crystal in a pore is thus an important parameter influencing the salt decay of porous rocks. The simplest way to calculate crystallization pressure was published by Correns [5] (Eq. 1) where $V_{x}$ is molar volume of crystal and ratio of concentrations is degree of supersaturation $\left(c_{298}\right.$ is initial concentration of solution and $c_{s}$ saturated concentration at temperature of crystallization.

$$
p_{\text {corr }}=\frac{R T}{V_{x}} \ln \frac{c_{298}}{c_{s}}
$$

Crystallization pressure according Eq. 1 does not take into account size of the pore where crystallization takes place. Fitzner and Snethlage [6] assumed that crystallization takes place primarily in larger pores (radius $R$ ) and after their filling it continues to smaller pores $(r)$; crystallization pressure than can be calculated from (Eq. 2) by help of interfacial tension between saturated solution and crystal $\sigma$. This approach was used also by Rossi-Maranesi and Tucci [7]; the pore size distribution curve was divided to five intervals (orders) and crystallization pressure generated in each of them $\left(p_{i}\right)$ (Eq. 2) was multiplied by ratio of pore interval volume $V_{r i}$ and volume of larger fraction $V_{R}$ (Eq. 3). Estimation of interfacial tension $\sigma$ is necessary in order to calculate crystallization pressure by Eqs. 2 and 3; the correlation equation (Eq. 4) for soluble salts was used in this work [8].

$$
\begin{gathered}
p_{f s}=2 \sigma\left(\frac{1}{r}-\frac{1}{R}\right) \\
p_{r m t}=\sum_{i} p_{i}\left(\frac{V_{r i}}{V_{R}}\right) \\
\sigma=-9 \cdot \log c_{s a t}+29.8
\end{gathered}
$$

The aim of this paper is to identify a reasonable relationship between durability of porous rocks and their mechanical a texture properties. Several estimators were proposed in order to relate "dry weight loss" $(D W L)$ acquired by a salt cycling experiment. Richardson [9] found a linear relationship between $D W L$ and parameter $D$ (Eq. 5) involving saturation coefficient (ratio of porosity obtained by capillary imbibition $P_{a}$ and total porosity $P$ ) a porosity. Modd et al. [10] proposed 
several estimators based on microporosity $P_{m}$ (defined for pores of diameter lower than $5 \mu \mathrm{m})$ such are e.g. $P_{m} \cdot C_{\text {sat }}$ (Est. 1); $P_{m}^{C_{\text {sat }}}($ Est. 2$)$ or $\left(P_{m}^{C_{\text {sat }}}\right)^{0.5}$ (Est. 3).

$$
D=\left(\frac{P_{a}}{P}\right)^{2} P=C_{\text {sat }}^{2} P
$$

Benavente et al. introduced several estimators based on "durability dimensional estimator" DDE (Eq. 6) which further involves flexural strength $\sigma \mathrm{F}$, compressive strength $\sigma \mathrm{C}$ and Young's modulus E (Eqs. 7-9 for DDE in $\mu \mathrm{m}-1$ ). DDE is a measure which should replace the pore size distribution curve DV(ri).

$$
\begin{gathered}
D D E=\sum \frac{D_{V}\left(r_{i}\right)}{r_{i}} P \\
P D E_{F}[\mathrm{~m} / \mathrm{kg}]=10 \frac{D D E}{\sigma_{F}} \\
P D E_{C}[\mathrm{~m} / \mathrm{kg}]=10 \frac{D D E}{\sigma_{C}} \\
P D E_{E}[\mathrm{~mm} / \mathrm{kg}]=10 \frac{D D E}{E}
\end{gathered}
$$

\section{Experimental}

The unconfined compressive strength of rocks was tested on cubic specimens (100 $\mathrm{mm}$ edge); the flexural strength was determined by help of $100 \times 100 \times 300 \mathrm{~mm}$ specimens. The specimens were stored in laboratory conditions. Dynamic Young's modulus was determined by means of ultrasonic pulse velocity measurement. The pore size distribution, total porosity $(P)$ and microporosity $\left(P_{m}\right)$ were estimated by mercury intrusion porosimetry (MIP; device Pascal 140 and 440 , Thermo) performed on dried samples. Saturation coefficient was determined as ratio of porosity acquired from stone capillary imbibition $\left(P_{a}\right)$ and total porosity from MIP. Sensitivity of stones to salt crystallization was tested by methodology developed and rationalized by Benavente et al. [12]. It consists in cycling of prismatic $(25 \times 25 \times 40 \mathrm{~mm})$ rock samples between "dissolution phase" $\left(40^{\circ} \mathrm{C}\right.$, $80 \% \mathrm{RH})$ and "crystallization phase" $\left(10^{\circ} \mathrm{C}, 70 \% \mathrm{RH}\right)$. The specimens have been partially $\left(5 \mathrm{~mm}\right.$ ) immersed in solution of $\mathrm{Na}_{2} \mathrm{SO}_{4}(14 \mathrm{w} / \mathrm{w} \%)$; the solution have been changed after each three cycles. Mirabilite $\left(\mathrm{Na}_{2} \mathrm{SO}_{4} \cdot 10 \mathrm{H}_{2} \mathrm{O}\right)$ is crystallizing and dissolving during the cycles. Each "phase" takes 12 hours; the cycling is performed automatically in climatic chamber. The experiment has been evaluated by means of "dry weight loss" $(D W L)$ - difference of stone mass before and after cycling.

\section{Materials}

Four kinds of sandstone excavated in Czech Republic were studied. They were selected with respect to wide range of their properties. Fig. 1 provides their appearance in SEM microphotographs. Božanov sandstone (B) is white-gray coarse grain arkosic cretaceous sandstone. Most of clasts are quartz but also K- 
feldspar and other silicates are present. Clasts are partially silicificated, there is an accessory clay matrix. Hořice sandstone $(\mathrm{H})$ is white-gray fine grain cenomanian stone with higher amount of clay matrix. Partial silicification and limonization of highly dominating quartz clasts have been observed. Fine grain quartz clasts are forming Mšené sandstone (M), there is just accessory of K-feldspars and muscovite. The rock contains negligible amount of matrix containing quartz dust, muscovite and kaolinite; the main diagenetic process is just weak silicification of clasts. Těšín arcosic sandstone $(\mathrm{T})$ is green-gray fine grain cretaceous stone with low porosity. The clasts are quartz, K-feldspar and muscovite, recrystallized calcite and silicified quartz dust are forming dense matrix.

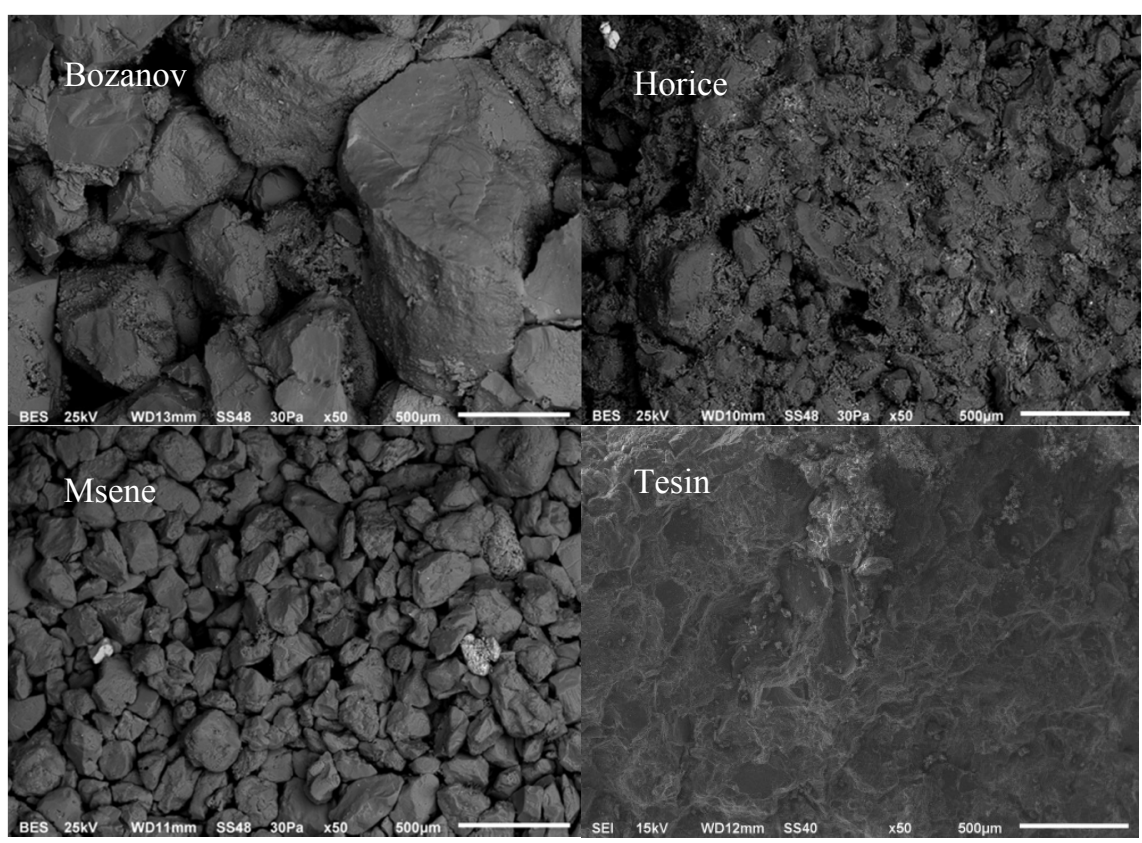

Figure 1: SEM microphotographs of studied rocks.

Fundamental properties of rocks under study are summarized in Tab. 1. Mechanical properties have been found in expected agreement with porosity; $\mathrm{T}$ has the lowest porosity due to its dense matrix which ensures the best mechanical properties. Sandstone B does not contain lot of matrix but its coarse grains results to relatively low porosity and good mechanical properties. The total porosity of stones $\mathrm{H}$ and $\mathrm{M}$ is nearly equal but mechanical properties of $\mathrm{M}$ are poorer because its clasts are bounded just by weak silicification. It is distinct especially on very low value of Young's modulus. Value of $P_{a}$ of $\mathrm{B}, \mathrm{H}$ and $\mathrm{M}$ is close (or equal) to total porosity what indicates high accessibility of pore system to water. Only T has fairly low $P_{a}$ what is related to low connectivity of pores in this material. 
Table 1: Properties of studied rocks.

\begin{tabular}{|c|c|c|c|c|c|c|}
\cline { 4 - 7 } \multicolumn{2}{|c|}{} & Božanov & Hořice & Mšené & Těš́n \\
\hline $\begin{array}{c}\text { Flexural } \\
\text { strength }\end{array}$ & $\sigma_{F}$ & $\mathrm{MPa}$ & 3.1 & 3.3 & 1.3 & 11.7 \\
\hline $\begin{array}{c}\text { Compressive } \\
\text { strength }\end{array}$ & $\sigma_{C}$ & $\mathrm{MPa}$ & 22.6 & 14.6 & 8.7 & 65.7 \\
\hline $\begin{array}{c}\text { Young's } \\
\text { modulus }\end{array}$ & $E$ & $\mathrm{GPa}$ & 20 & 22.6 & 10.9 & 39.3 \\
\hline Porosity & $P$ & $\%$ & 16.8 & 27.3 & 28.2 & 7.2 \\
\hline $\begin{array}{c}\text { Absorption } \\
\text { porosity }\end{array}$ & $P_{a}$ & $\%$ & 16.4 & 23.6 & 28.2 & 4.7 \\
\hline $\begin{array}{c}\text { Micro- } \\
\text { porosity }\end{array}$ & $P_{m}$ & $\%$ & 2.7 & 4.7 & 1.5 & 6.6 \\
\hline
\end{tabular}

More information about pore system is providing MIP (Fig. 2). B, H and M sandstones contain significant amounts of capillary pores of diameter around $100 \mu \mathrm{m}$. Fine pores $(0.1-1 \mu \mathrm{m})$ are in these rocks present due to clay matrix; it is found in highest amount in $\mathrm{H}$ while $\mathrm{M}$ contains nearly any matrix - and also nearly any of these small pores. The contribution of such small (diameter $<1 \mu \mathrm{m}$ ) pores to the total porosity was denoted as microporosity $P_{m}$. The absolutely and also relatively $\left(P_{m} / P\right)$ highest microporosity was detected in $\mathrm{T}$; on the other hand the lowest microporosity has $\mathrm{M}$, again due to absence of matrix.

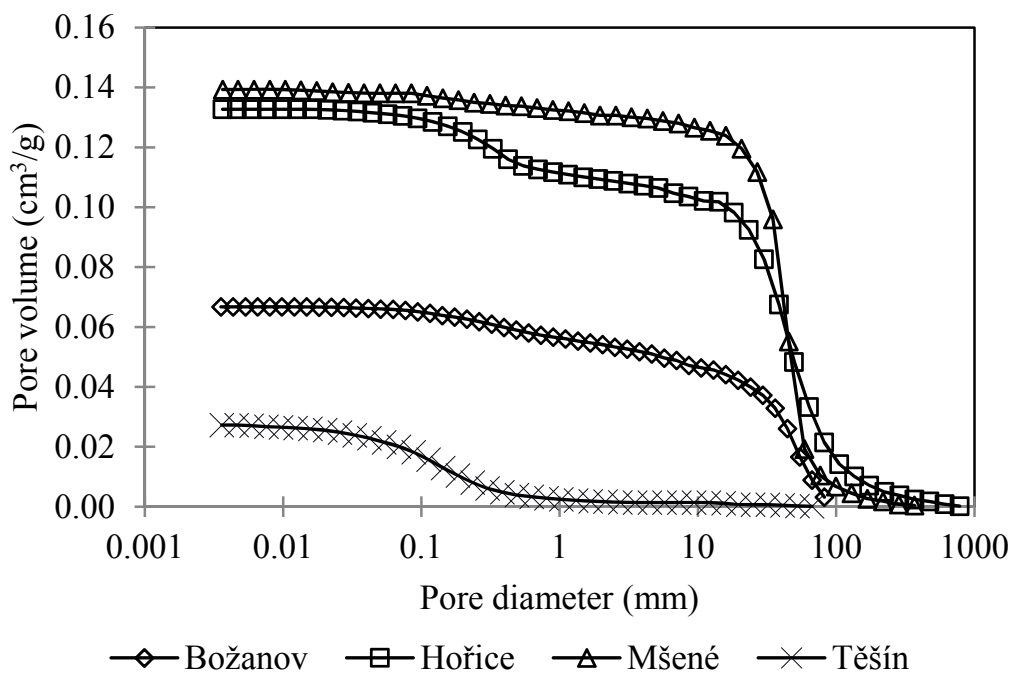

Figure 2: $\quad$ Pore size distribution of studied rocks. 


\section{Results and discussion}

Results of salt cycling experiments are given in Tab. 2. In all cases the stone's deterioration took place just on edges of specimens. When one compares values of $D W L$ with mechanical properties and total porosity (Tab. 1) of rocks there is not any simple correlation. The highest $D W L$ has had stone $\mathrm{T}$ with highest strength and lowest porosity. On the other hand the best performance has had stone porous $\mathrm{M}$ with poor mechanical properties.

Table 2: Results of cycling experiment.

\begin{tabular}{|l|c|}
\cline { 2 - 2 } \multicolumn{1}{c|}{} & DWL (\%) \\
\hline Božanov & 1.58 \\
\hline Hořice & 2.98 \\
\hline Mšené & 1.26 \\
\hline Těšín & 3.07 \\
\hline
\end{tabular}

The explanation has to be searched in pore size distribution (Fig. 2). Relationships for crystallization pressure calculation (Eqs. 2 and 3) clearly indicate that higher crystallization pressure is generated in smaller pores "micropores" which are present especially in H and T. Qualitatively it seems that rocks microporosity is the key factor influencing $D W L$ regardless the stone's strength. Fig. 3 shows the linear relationship between $D W L$ and $P_{m}$.

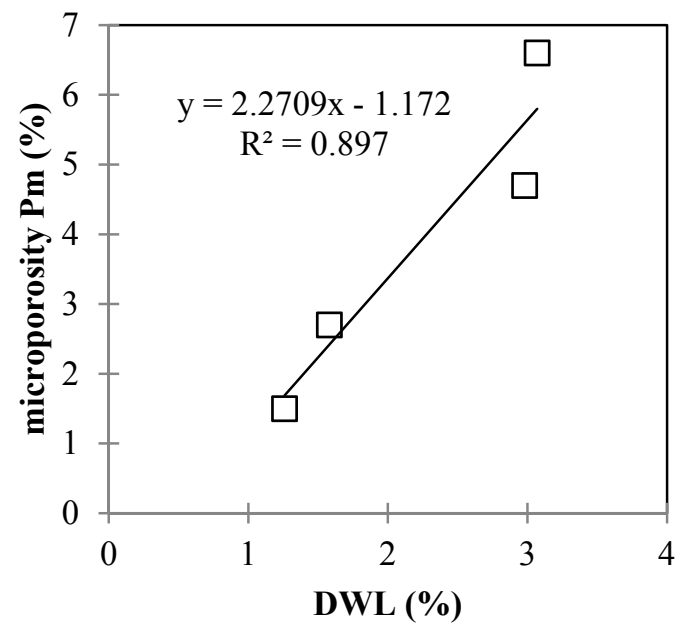

Figure 3: Relationship of DWL and Pm of studied rocks.

Correlation of $D W L$ and durability estimators based on pore system characteristics (Fig. 4) revealed that estimator $D$ (Eq. 5) completely failed for studied rocks, probably due to absence of a measure of pore size distribution. The 
Modd et al. estimators [10] performed better, especially Est. $1\left(P_{m} \cdot C_{s a t}\right)$ provided fair linear correlation. Modd et al. [10] obtained the best results with Est. 3 $\left(\left(P_{m}^{C_{s a t}}\right)^{0.5}\right)$. It should be noted that they studied very large specimens' pool. The correlation between $D D E$ and durability estimators (Eqs. 7-9) based on mechanical properties was also tested but the results were scattered.

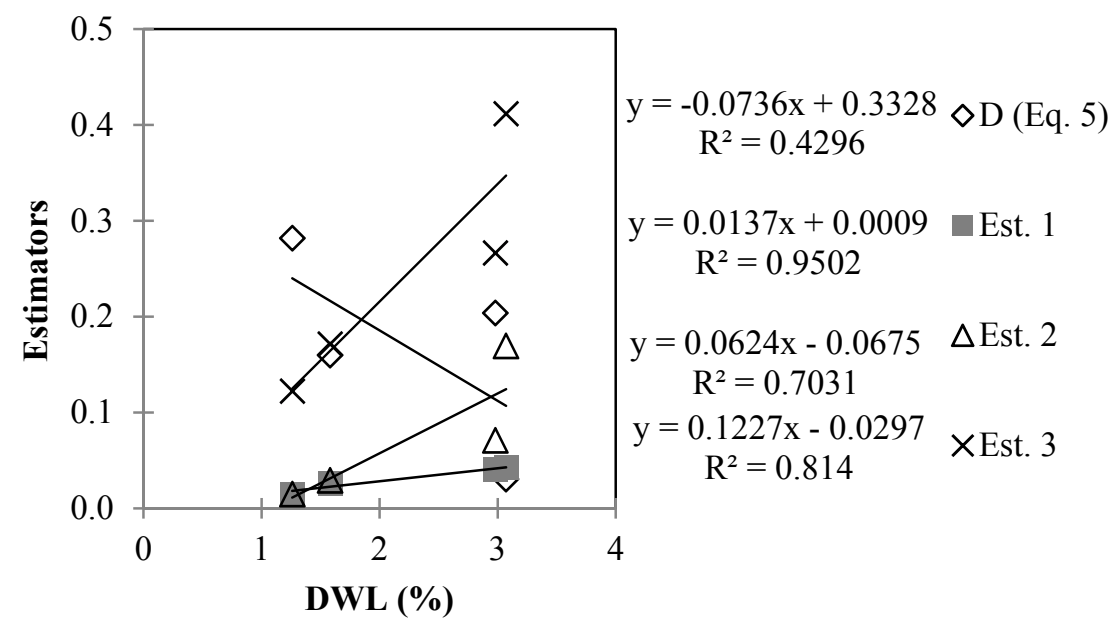

Figure 4: Relationship of $D W L$ and durability estimators based on pore system characteristics.

Crystallization pressure of $\mathrm{Na}_{2} \mathrm{SO}_{4} \cdot 10 \mathrm{H}_{2} \mathrm{O}$ at given temperature according to Eq. 1 is $5.9 \mathrm{MPa}$. This value cannot explain difference in $D W L$ of various rocks since it does not reflect the pore size distribution. Method of Fitzner and Snethlage (Eq. 2) was tested in two variations (Tab. 3). Interfacial tension (Eq. 4) was calculated to be $32 \mathrm{mN} / \mathrm{m}$. Firstly, broader pore size range, covering all present pores, was assumed. Secondly just narrow interval of pore size distribution curve, where the rock-character determining pores are present, was used for calculation. The assumed broader interval provides values significantly higher than flexural strength of rocks what does not correspond with relatively low $D W L$ obtained. The narrow pore size interval provides better correlation with $D W L$ (Fig. 5). The method according Eq. 3 assumes dividing of pore size distribution curve to several intervals (classes). Rossi-Maranesi and Tucci [7] used a constant value of $R$ assuming that crystallization in all classes of smaller pores starts from same large spaces. This assumption has not to be necessarily fulfilled; crystallization can proceed also successively through all (or some) present classes. The realistic quantification of both possibilities is impracticable but both approaches provide different results. The calculated value of crystallization pressure also depends on chosen number of pore classes. For that reasons we believe the crystallization pressure calculated according to Eq. 2, where just pores responsible for determining the rock's nature are taken into account, is more realistic. 
Table 3: Crystallization pressures calculated according to Eq. 2.

\begin{tabular}{|l|c|c|c|}
\cline { 2 - 4 } \multicolumn{1}{c|}{} & $\mathrm{R}$ & $\mathrm{r}$ & $\mathrm{p}_{\mathrm{fs}}$ \\
\hline & $\mu \mathrm{m}$ & $\mu \mathrm{m}$ & $\mathrm{MPa}$ \\
\hline & \multicolumn{3}{c|}{ broad } \\
\hline Božanov & 41 & 0.007 & 9.14 \\
\hline Hořice & 392 & 0.008 & 7.88 \\
\hline Mšené & 184 & 0.005 & 12.37 \\
\hline Těšín & 33 & 0.002 & 35.55 \\
\hline & \multicolumn{3}{|c|}{ narrow } \\
\hline Božanov & 41 & 0.050 & 1.28 \\
\hline Hořice & 200 & 0.015 & 4.27 \\
\hline Mšené & 60 & 0.050 & 1.28 \\
\hline Těšín & 25 & 0.010 & 6.40 \\
\hline
\end{tabular}

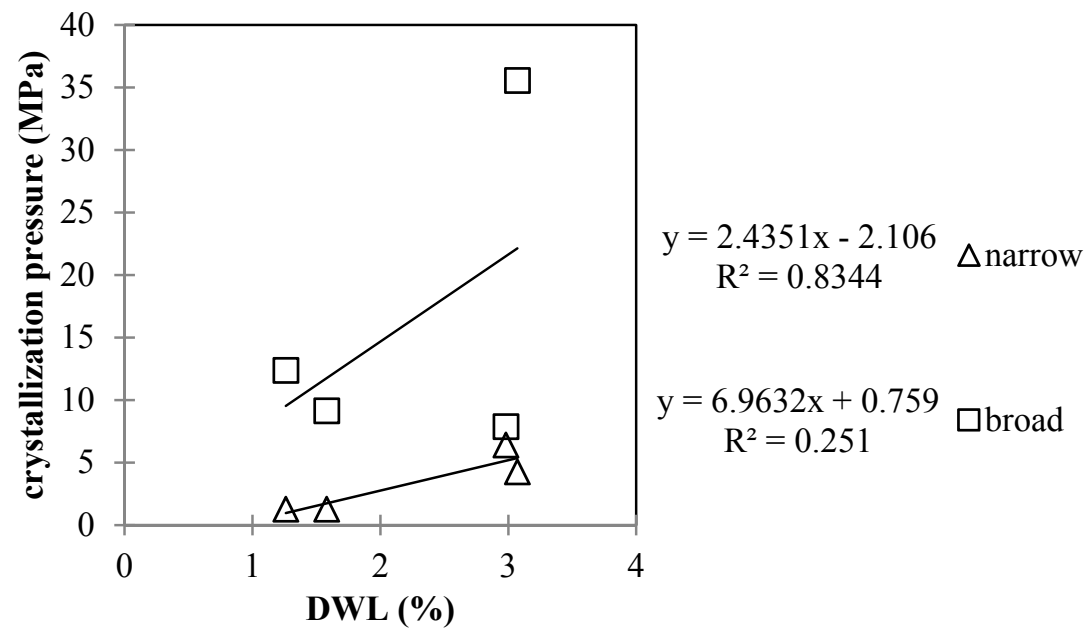

Figure 5: Relationship of $D W L$ and crystallization pressure according Fitzner and Snethlage.

\section{Conclusions}

The resistance of four kinds of sandstone of different petrophysical properties to sodium sulfate cyclic crystallization was studied. The experimental results indicated that volume of micropores has been the key factor controlling the $D W L$ while mechanical properties of rocks were not decisive. The presence of micropores is essential for generation of crystallization pressure. Various durability estimators were tested, the best linear fit with $D W L$ provided $P_{m} \cdot C_{s a t}$. 


\section{Acknowledgement}

This research has been supported by the Czech Science Foundation under project Nr. 14-17207S "Transport parameters and durability of porous rocks".

\section{References}

[1] Benavente, D., Cueto, N., Martínez-Martínez, J., García del Cura, M. A., Cañaveras, J. C. The influence of petrophysical properties on the salt weathering of porous building rocks. Environmental Geology 52 (2007), pp. 215-224.

[2] Ruedrich, J., Siegesmund, S. Salt and ice crystallization in porous sandstones. Environmental Geology 52 (2007), pp. 225-249.

[3] Přikryl, R., Lokajíček, T., Svobodová, J., Weishauptová, Z. Experimental weathering of marlstone from Přední Kopanina (Czech Republic) historical building stone of Prague. Building and Environment 38 (2003), pp. 1163-1171.

[4] Thaulow, N., Sahu S. Mechanism of concrete deterioration due to salt crystallization. Materials Characterization 53 (2003), pp. 123-127.

[5] Correns, C.W. Growth and dissolution of crystals under linear pressure. Faraday Discussions 5 (1949), pp. 267-271.

[6] Fitzner, B., Snethlage, R. Über Zussamenhange zwischen Salzkristallisationsdruck und Porenradienverteilung. G.P. Newsletter 3 (1982), pp. 13-24.

[7] Rossi-Maranesi, R., Tucci, A. Pore structure and the disruptive or cementing effect of salt crystallization in various types of stone. Studies in conservation 36 (1991), pp. 53-58.

[8] Söhnel, O. Electrolyte crystal - aqueous solution interfacial tensions from crystallization data. Journal of Crystal Growth 57 (1982), pp. 101-108.

[9] Richardson, B.A. The durability of porous stones. Stone Industries 26 (1991), pp. 22-25.

[10] Modd, B.K., Howarth, R.J., Bland, C.H. Rapid prediction of building research establishment limestone durability class from porosity and saturation. Quarterly Journal of Engineering Geology 29(1996), pp. 285297.

[11] Benavente, D., García del Cura, M.A., Fort, R., Ordónez, S. Durability estimation of porous building stones from pore structure and strength. Engineering Geology 74 (2004), pp. 113-127.

[12] Benavente, D., García del Cura, M.A., Bernabéu, A., Ordónez, S. Role of salt weathering in porous stones using an experimental continuous partial immersion method. Engineering Geology 59 (2001), pp. 313-325. 